\title{
An environmental friendly model for materials substitution in a fiberglass reinforced polyester composite
}

\author{
Eugen Axinte, ${ }^{1}$, Yan Wang ${ }^{2}$, Ahmad Majdi Abdul-Rani ${ }^{3}$, Abdul Azeez Abdu Aliyu', \\ Octavian Andronic ${ }^{1}$, Ciprian Stegaru ${ }^{1}$ and Andrei Bofu ${ }^{1}$ \\ ${ }^{1}$ Gheorghe Asachi Technical University of Iasi, Romania \\ ${ }^{2}$ School of Materials Science and Engineering, University of Jinan, Jinan, PR China \\ ${ }^{3}$ Universiti Teknologi Petronas, Seri Iskandar, Perak Darul Ridzuan, Malaysia
}

\begin{abstract}
In this work is presented an empirical developed model for materials substitution: an empirical established quantity of a fiberglass reinforced polyester composite (basic material) was substituted successively with two natural cheaper materials (natural wastes) resulted from other manufacturing processes. The experiment is purely empirical and no theory is developed in this work. The main scope is to observe if the new and cheapest materials can successful replace the much expensive basic materials in some industrial applications. The microstructures and some physical and mechanical properties of the new materials were studied by reporting to the basic material.
\end{abstract}

\section{Introduction}

Materials have a long history beginning with the age of natural materials (stone, copper, bronze and iron ages), continuing in last century with the age of polymers, of composites and ongoing with the molecular age-the age of functional materials such as graphene, biopolymers, smart and nano-structured materials [1].

In the $19^{\text {th }}$ and $20^{\text {th }}$ centuries the materials availability was not a major issue for industry (except in war periods).The main business model was one of "take-make -use -dispose with focus on economic growth". Today, materials become an important part of society sustainable development and the situation is entirely different: the materials are not so abundant reported to the increased desires of the global population. The technological development make us dependent on access to more and more elements of periodic table. Some materials very rare, expensive or/and important for national security of states are now classified as "critical materials", (i.e. platinum, tungsten, palladium or beryllium). The substitution of expensive materials with cheap materials but of same quality is a desire and a scope of materials scientists. Even when a material has proven satisfactory for a particular application, materials substitution should always be a consideration. Substitution may provide a reduction in cost or an opportunity to improve a design. Substitute materials must satisfy all economic, physical, and chemical requirements of the application. Materials

${ }^{*}$ Corresponding author: axintee@,tuiasi.ro 
substitution is often related to the development of new approaches to extraction or processing. A more complicated situation is that a product will contain many materials and have the potential for substitution of some of them. This is the case of automotive industry, where over the recent past the use of carbon steel, iron, and zinc die castings has dropped significantly and high strength steel, aluminum, copper (mostly electrical), and plastics use has risen substantially. Everywhere is possible, the natural fibers are now being used in fibers-reinforced plastic components, reducing the weight over glass-reinforced components and increasing the recyclability [2-4]. In past two decades the pursuing for new materials with high performances at lower costs are continuously growing. The increasing of environmental awareness directed some of this researches on eco-friendly materials, with properties such as renewable, recyclable or/and biodegradable. This underscores the emergence of a new type of materials - a change from non-renewable, but difficult to degrade or non-degradable, to renewable and easily degradable materials. The development and selection of a material which meet the optimum structural and design requirements conduct to compromises between conflicting objectives and this can be overcome by resorting to multi-objective optimization in material design and selection [5-6].Composite materials which are prepared using natural or synthetic reinforcements and a variety of matrix materials are included in this philosophy [7-20]. The development of such substitutive materials can be an important provider of opportunities to improve the standard of living of people around the world, especially on under-developed countries. Many of the actual renewable materials are based on agricultural and forestry products as a source of raw materials, particularly to plastic industries and these could generate a source of economic development for farming and rural areas in developing countries.

\section{Materials and method}

\subsection{The fabrication of the new raw materials and of the experimental samples}

The basic material for the new materials and for the samples fabrication is a commercially fiberglass reinforced polyester (FRP) composite. The composite is a type of polymer matrix composite (PMC) that uses discontinuous fibers randomly arranged pattern for reinforcement (see Figure 1, taken in the laboratory).

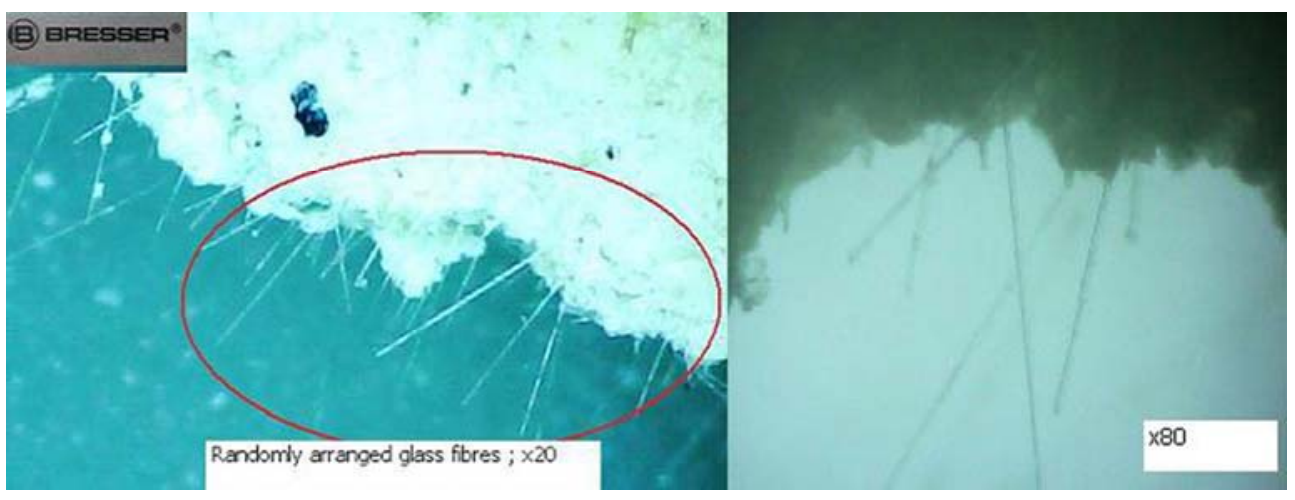

Fig. 1. Randomly arranged glass fibers in polymer matrix composite (x 20; x 80; instrument: Bresser Optical Digital Microscope-TCM Department).

Fiberglass is a usual type of reinforcement used in PMCs due to its high strength to weight ratio and could improve the tensile strength and modulus of the polymer matrix. The composite is commercially delivered as a bi-component composite: polyester with 
fiberglass (97 \%) and Dibenzoyl Peroxide paste (DBPO 2-4\%) as cross linker. The composition of the basic material was determined by X-ray dispersive energy analyze EDAX by using an EDAX UHV-Si (Li) detector. It was used the Esprit software (mode Auto and listing by database PB-ZAF). The results are listed in Figure 2.
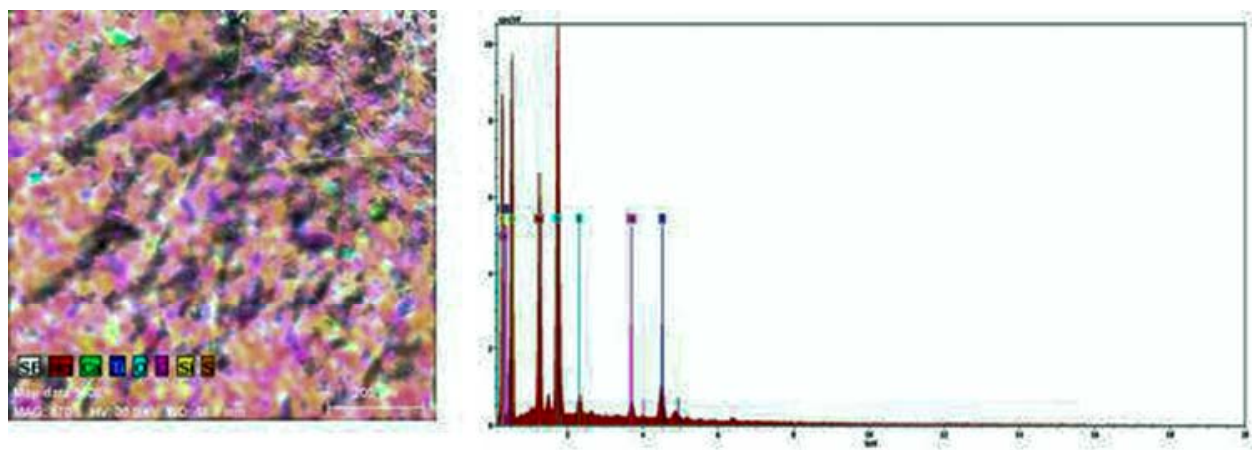

Fig. 2. The spectroscopic analyze of basic material (fiberglass reinforced polyester).

It were fabricated two another composites materials by replacing successively a small quantity ( $1 \mathrm{~g}$ - represents $4 \%$ in weight) of basic material with another two raw materials: wood pellets and carbon pellets. The wood pellets are obtained by sifting the sawdust of agglomerate wooden boards and the carbon pellets are obtained from sifted grounded wood charcoal. The measured specific weight of wood pellets is $0.24 \mathrm{~g} / \mathrm{cm}^{3}$ and the density of carbon pellets is $0.33 \mathrm{~g} / \mathrm{cm}^{3}$. The maximum size of pellet-diameter of idealized pellet assimilated to a sphere is $\mathrm{d}_{\max }=0.71 \mathrm{~mm}$ ( $\operatorname{sift}-$ Mesh $25 \mathrm{us}$ ).

Table 1. Some physic and commercial properties of composites.

\begin{tabular}{|l|l|l|l|}
\hline \multicolumn{1}{|c|}{ Material } & \multicolumn{1}{|c|}{ Dimension $(\max ), \mathrm{mm}$} & \multicolumn{1}{|c|}{ Density, $\mathrm{g} / \mathrm{cm}^{3}$} & \multicolumn{1}{c|}{ Price, $\mathrm{USD} / \mathrm{kg}$} \\
\hline FRP composite & paste & 2.15 green & 10 \\
\hline Wood pellets Wp & 0.71 & 0.24 & 0 \\
\hline Carbon pellets $\mathrm{Cp}$ & 0.71 & 0.33 & 0 \\
\hline
\end{tabular}

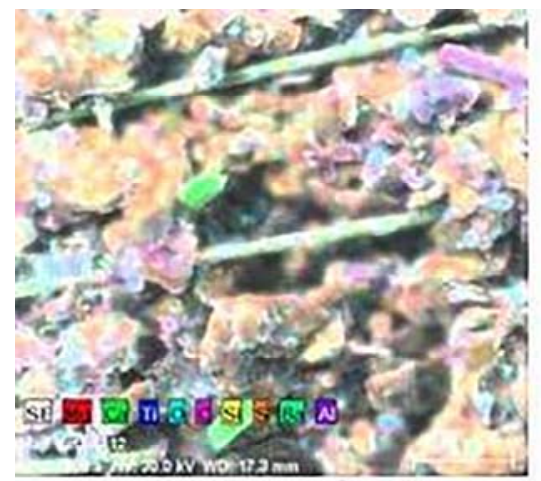

a. FRP+wood pellets

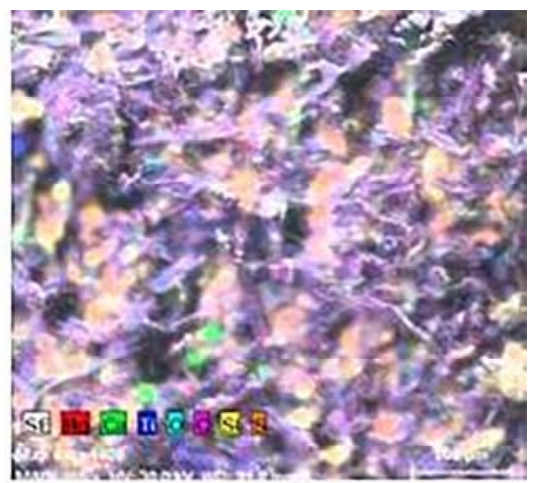

b.FRP+carbon pellets

Fig. 3.The spectroscopic analyze of fiberglass reinforced polyester combined with a) wood pellets b) carbon pellets.

The chemical compositions of the new produced materials were determined by EDAX analysis and the spectroscopic analysis of the two new materials is presented in Figure 3 (a, b). It's observed the apparition of a small percent of aluminum in the composition of FRP mixed with wood pellets- the only explanation of this phenomenon is that the adhesive of agglomerate wooden boards contains aluminum oxide or another compound of Al. The raw 
mixtures were mechanically mixed then there were shaped in mold (cylinder with $45 \mathrm{~mm}$ in diameter and $7 \mathrm{~mm}$ in height ) and dried for 24 hours at $35^{\circ} \mathrm{C}$ in drying stove. The obtained samples are discs with $45 \mathrm{~mm}$ diameter with different colors and heights.

The final heights of dried samples were measured with a digital caliper. The final weights of the obtained samples were weighed with a precision micro-balance type $\mathrm{MH}$ Series (0$500 \mathrm{~g} /$ precision $0.1 \mathrm{~g}$ ) - see Figure 4.
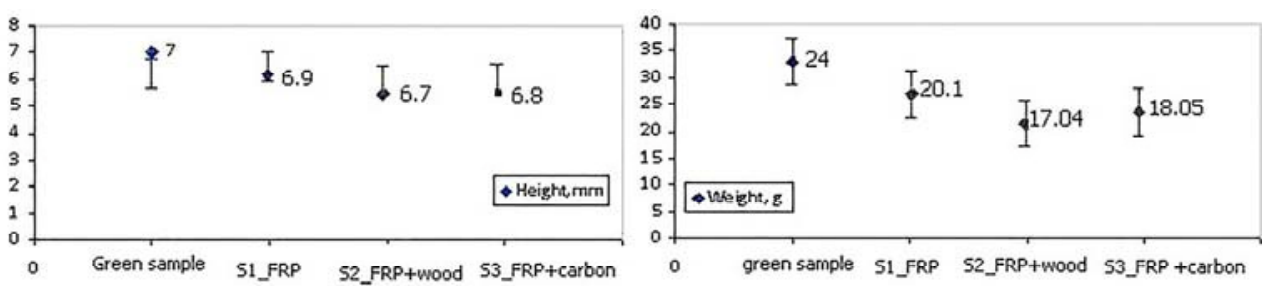

Fig. 4. The heights and the weights of dried samples.

The microstructure of the basic material and of the new materials was analyzed by scanning electron microscopy SEM using the Scanning Electron Microscope VegaTescan LMH II Detector SE. There were used different magnification powers and the results are presented in Figures 5-6.

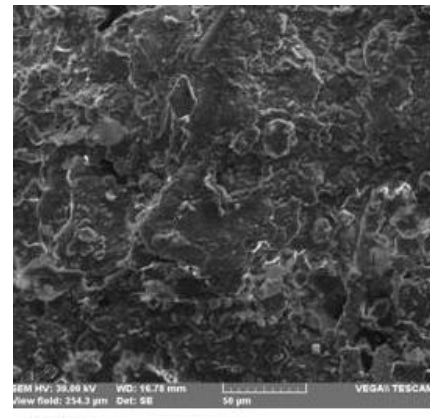

$1000 x$

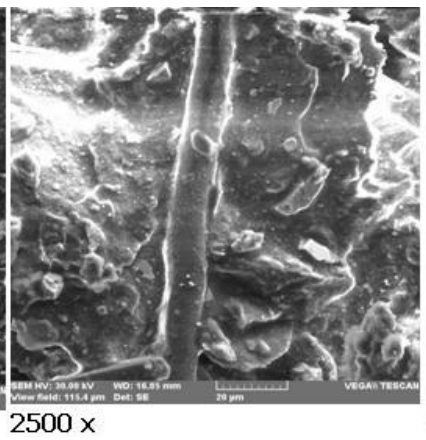

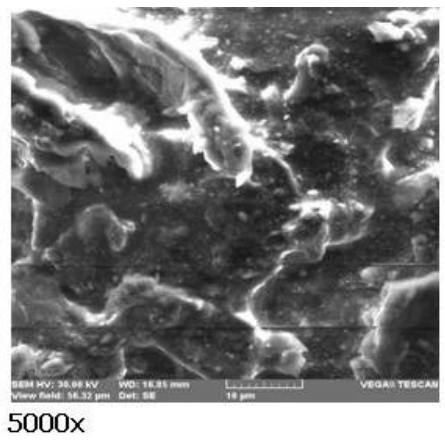

Fig. 5. SEM images of dried basic material (Sample 1) - fiberglass reinforced polyester FRP, at different magnification powers.

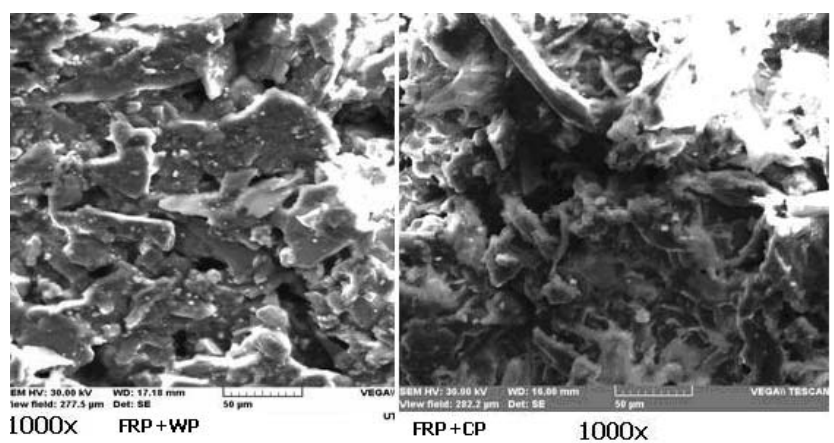

Fig. 6. SEM images of FRP mixed with wood pellets and carbon pellets.

The SEM analysis of samples revealed a dense and relatively homogenous structure of fiberglass reinforced polyester FRP. Also the analysis revealed the quasi-porous structures at FRP mixed with wood and carbon pellets. 


\section{Results and discussion}

\subsection{Noise level conduction characteristics}

For evaluate the noise and the heat transmitting characteristic of the materials the samples are prepared as it follows: all the samples are double front-wall abrasive polished (on an abrasive plate) to an equal height of $5.50 \mathrm{~mm}$.

An insulating box was fabricated for this research. The box have a upper insulating cover with a circular hole (hole diameter $=30 \mathrm{~mm}$ ).

A noise generator was introduced in the box and were measured the noise levels in four distinct situations - with the hole free and with the three samples successively covering the hole.

A sound level meter type Chauvin Arnoux CA 834 with the SE 232 data recording software was used for noise measurements (see schematic setup in Figure 7).

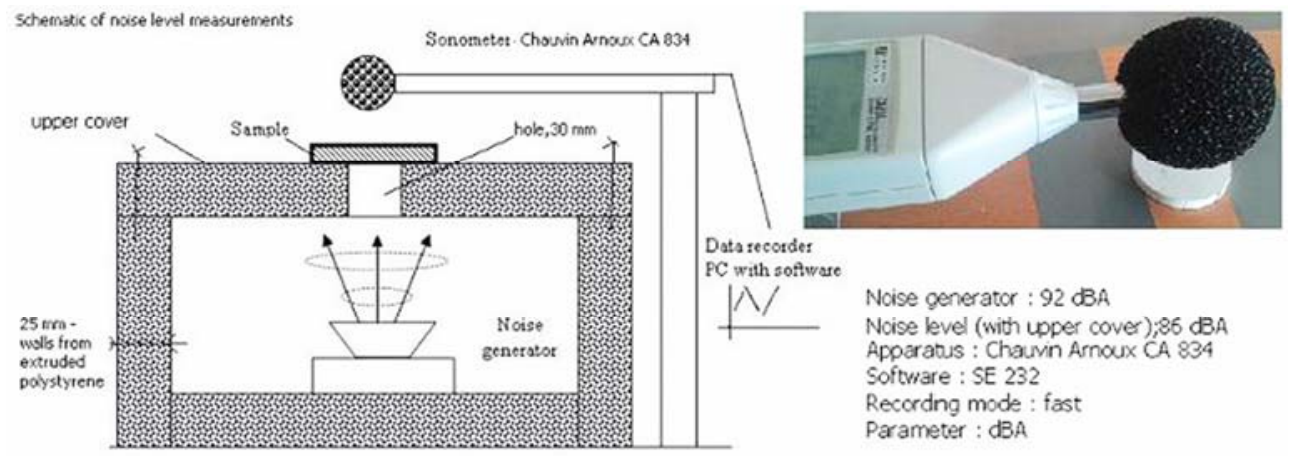

Fig. 7. Schematic of noise level measurements setup.

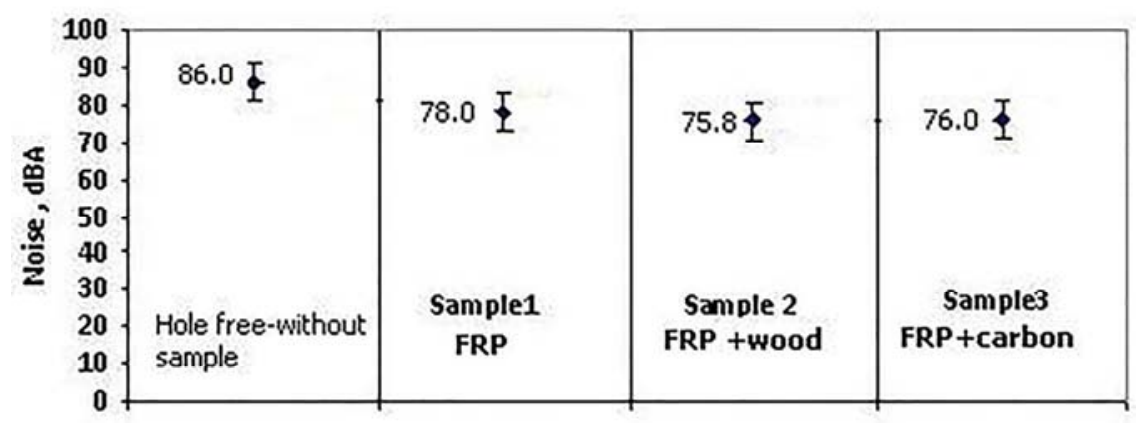

Fig. 8. Comparative noise level conduction of the three materials.

There were obtained the following results: at measurement of noise level outside the box with the hole free, the noise level was of $86 \mathrm{dBA}$.

The results of noise levels with the hole covered successively by three samples are presented in Figure 8. It is observed a reduction of noise level with 8 to $10.2 \mathrm{dBA}$.

Its easy observable that the best noise insulation $(-10.2 \mathrm{dBA})$ is offered by the fiberglass reinforced polyester combined with wood pellets. 


\subsection{Machinability of samples}
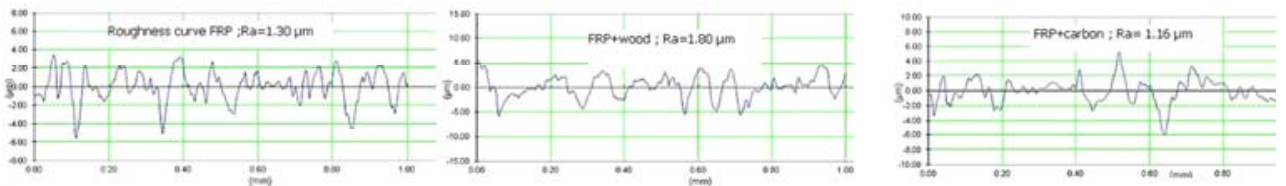

Fig. 9. The roughness and the profile curves of polished samples.

All the samples are double front-wall abrasive roughed on an abrasive plate (abrasive paper P80)and final polished (abrasive paper P150 ) to a height of $5.50 \mathrm{~mm}$ (see the Figure 10 ).The obtained roughness and the profile characteristics were measured with Handysurf EMC-S24B with dedicated software TextDataOutput Tool ver.2.4. The smallest roughness, $\mathrm{Ra}=1.16 \mu \mathrm{m}$ was obtained at polished FRP mixed with carbon pellets as it observed in Figure 9.

\subsection{Microhardness determination by static indentation}

Microhardness test usually refers to static indentations made with loads not exceeding 1 kgf. The indenter is the Vickers diamond pyramid and the procedure for testing is similar to that of the standard Vickers hardness test, except that it is done on a microscopic scale with higher precision instruments. [21-22]. The surface being tested generally requires a fine polishing and the smaller the load is used, the higher the surface finish is required[23].For easier observation the surface samples were sprayed with metallic grey paint. In this experiment it was used the Digital Micro Hardness Tester DM2A (Affri®) with the dedicated software Taurus. The test force used was $0.9807 \mathrm{~N}(100 \mathrm{gF})$ and the loading time was $\mathrm{t}=5$ seconds. There were made five loads for every sample on different places and diameters and finally was used the average value. The microhardnesses of the three materials obtained by static indentation are presented in the comparative graph from Figure 10. It was determined that FRP and FRP+Wp have close values of hardness and a bigger hardness value $(+10 \%)$ is observed at FRP mixed with carbon pellets.

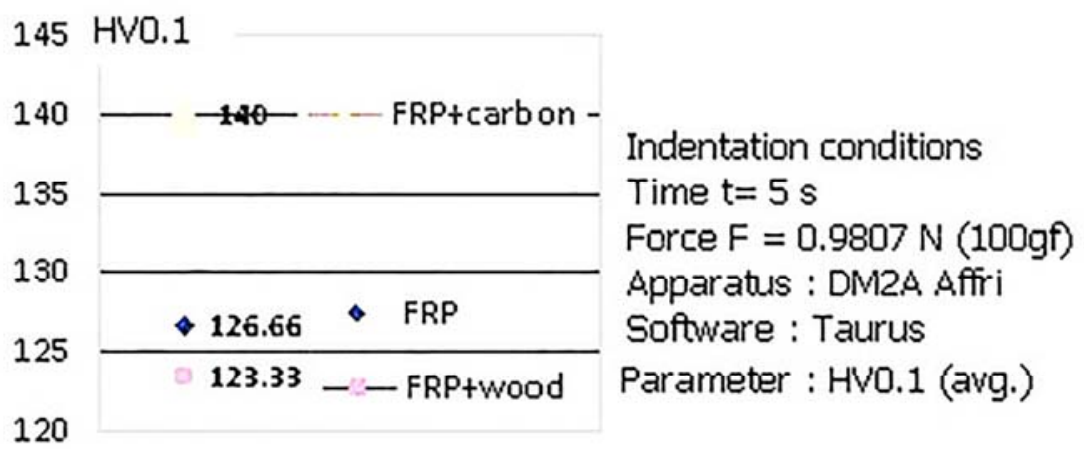

Fig. 10. The average microhardness $H_{0.1}$ of the three materials.

\subsection{Temperature transmitting characteristics of the samples}

For measuring the temperature transmitting characteristics in conduction heating was used an experimental setup schematic presented in Figure 11a. The temperature of the rheostat heater was electronic maintained constant $\left(\theta_{0}=200^{\circ} \mathrm{C}\right)$ and the measurements were made at 
variable times until the thermodynamic equilibrium. The temperature transmitting distribution and evaluation in conduction heating of samples is illustrated in Figure 11b and $11 \mathrm{c}$.
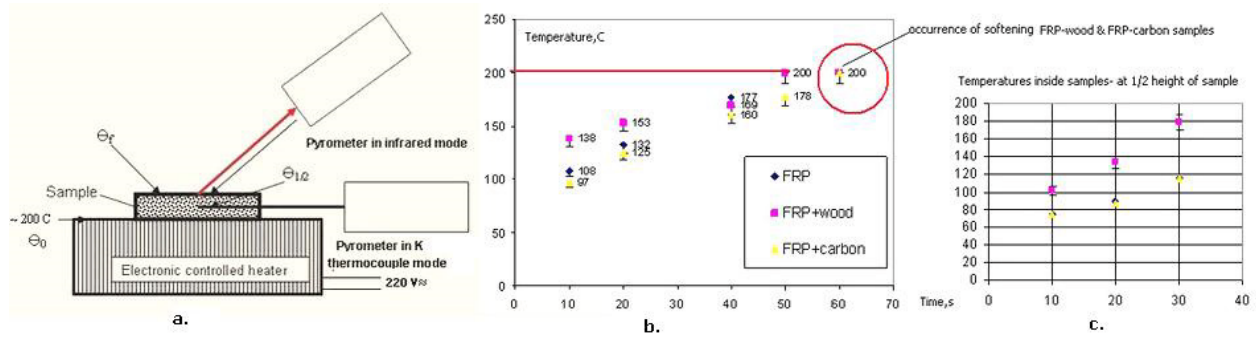

Fig. 11. Temperature transmitting measurement in conduction heating a. setup scheme b. temperature transmitting at surface $c$. temperature transmitting at middle of sample.

The thermodynamic equilibrium is realized by FRP and FRP $+\mathrm{Wp}$ after 50 seconds of heating and by FRP + $\mathrm{Cp}$ after 60 seconds of heating. Also is the observed that the FRP+ $\mathrm{Cp}$ has the lower thermal conductivity. At $200{ }^{\circ} \mathrm{C}$, meanwhile FRP is stable, it was observed that the both new materials (FRP - wood/ FRP-carbon) suffers a softening process.

\section{Conclusions}

By replacing a small quantity (1\% in weight) of fiberglass reinforced polyester with wastes (wood pellets and charcoal pellets) another two composite materials were successful fabricated. The small quantity of material substituted is dictated by the low specific weight (and relatively big volume) of substitution materials. The SEM analysis revealed the dense microstructure structure of fiberglass reinforced polyester FRP.

Also, the analysis revealed a porous structure at FRP mixed with wood and a quasi-porous structure at FRP mixed carbon pellets. Microhardness tests performed by static indentation determined that FRP and FRP+ wood have closer value of hardness. A bigger hardness value is observed at FRP mixed with carbon pellets.

All the preliminary results indicate that exists the real possibility for substitution of small quantity of expensive materials with raw cheaper materials without major affecting the final quality and some functional properties of the new obtained materials.

\section{References}

1. M. F. Ashby Materials and Sustainable Development. Butterworth-Heinemann, Oxford Eng., UK, 2015

2. B. R. Allenby, T. E. Graedel, Industrial Ecology. Prentice-Hall, Englewood Cliffs, N.J. 1993

3. $\mathrm{H}$. $\mathrm{Ku}$ et al., A review on the tensile properties of natural fiber reinforced polymer composites Composites Part B: Engineering 42, 856-873 (2011)

4. Q. Wang, M. Zhang, Y. Cai, L. Shu, CAE Optimization and Design of Injection Mould with Inner Parting Structure for Automobile Front Bumper. Recent Patents on Materials Science 9 (1), 58-63 (2016)

5. F. Negoescu, E. Axinte, G. Nagît, A. Iosub, Innovative solutions creates environmental advantages. Environmental Engineering \& Management Journal 8 (5), $1-8(2009)$ 
6. A. Jahan, K. L. Edwards, Weighting of dependent and target-based criteria for optimal decision-making in materials selection process: Biomedical applications. Materials\& Design 49, 1000-1008 (2013)

7. J. Summerscales, N. P. J. Dissanayake, A.S. Virk, W. Hall, A review of bats fibers and their composites. Part 1 - Fibers as reinforcements. Composites Part A: Applied Science and Manufacturing, 41, 1329-1335 (2010)

8. Z. Sun, Q. Xing, E. Axinte, Ge. W, J. Leng, Yan Wang Formation of highly thermal stable Al 88 Ni 6 Y 6 amorphous composite by graphene addition design. Materials \& Design 81, 59-64 (2015)

9. K. G. Satyanarayana, G. G. C. Arizaga, F. Wypych, Biodegradable composites based on lignocellulose fibers - an overview. Progress in Polymer Science 34, 982-1021 (2009)

10. N. Venkateshwaran, A. Elayaperumal, Banana fiber reinforced polymer composites - a review. Journal of Reinforced Plastics and Composites 29, 2387-2396 (2010)

11. M. J. John, S. Thomas, Review - biofibres and biocomposites. Carbohydrate Polymers, 71, 343-64 (2008)

12. S. Shinoja, R. Visvanathanb, S. Panigrahic, M. Kochubabua, Oil palm fiber (OPF) and its composites: a review. Industrial Crops and Products 33, 7-22 (2011)

13. A. K. Mohanty, M. Misra, G. Hinrichsen, Biofibers, biodegradable polymers and biocomposites: an overview. Macromolecular Materials and Engineering 276, 1-24 (2000)

14. A. Hassan, A. A. Salema, F. H. Ani, A. A. Bakar, A review on oil palm empty fruit bunch fiber-reinforced polymer composite materials. Polymer Composites 31, 2079101 (2010)

15. R. R. Franck (Ed.), Bast and other plant fibers. CRC Press, Boca Raton, Florida, 2005

16. Y. Libo, B. Kasal, L. Huang, A review of recent research on the use of cellulosic fibers, their fiber fabric reinforced cementations, geo-polymer and polymer composites in civil engineering Composites Part B: Engineering 92, 94-132 (2016)

17. A. K. Bledzki, V. E. Sperber, O. Faruk, Natural and wood fiber reinforcements in polymers. Rapra Review Report 13 (8), 1-144 (2002)

18. O. Faruk, A. K. Bledzki, H. P. Fink, M. Sain, Biocomposites reinforced with natural fibers: 2000-2010. Progress in polymer science 37 (11), 1552-1596 (2015)

19. G. Koronis, A. Silva, M. Fontul, Green composites: a review of adequate materials for automotive applications. Composites Part B: Engineering 44 (1), 120-127 (2013)

20. K. L. Edwards, E. Axinte, L. L. Tabacaru, A critical study of the emergence of glass and glassy metals as "green" materials, Materials \& Design 50, 713-723 (2013)

21. D. Chicot et al., Some improvements for determining the hardness of homogeneous materials from the work-of-indentation. International Journal of Mechanical Sciences 105, 279-290 (2016)

22. W. C. Oliver, G. M. Pharr, Measurement of hardness and elastic modulus by instrumented indentation: Advances in understanding and refinements to methodology, Journal of Materials Research 01, 3-20 (2004)

23. J. G. Kohl, N. Bierwisch, T. T. Ngo, G. Favaro, E. Renget, N. Schwarzer, Determining the viscoelastic behavior of polyester fiberglass composite by continuous microindentation and friction properties. Wear 350, 63-67 (2016) 